\title{
Correspondence:
}

\section{Doctor as a healer}

From time immemorial the doctor or physician or vaidya has been given the highest respect in Indian tradition. Numerous anecdotes describe the sacred relationship between doctors and their patients. Unfortunately with increasing commercialization the equation has changed. India is a free country with everyone having the right to freedom of speech. In a recent television episode, the views expressed by film actor Aamir Khan were received with a lot of hue and cry, especially by the medical fraternity. The related issues were discussed at length in various forums throughout the country. The editorial published in Indian Journal of Urology entitled "Should Mr. Aamir Khan apologize - Medical professionalism in crisis" by
Professor Kekre, highlighted certain issues, like quality of medical education, doctor-patient relationship and ethics in medicine. ${ }^{1}$

Definitely some changes are required in our system. By considering the reaction to the above mentioned television episode, we think the medical fraternity, should introspect, identify the problematic areas, overhaul the existing medical education system and ultimately offer realistic, achievable and reasonable solution to the society in general. Only then we can hope to bridge the gap between the patients and their healers.

\section{REFERENCES}

1. Kekre NS. Should Mr. Aamir Khan apologize - Medical professionalism in crisis. Indian $\mathrm{J}$ Urol 2012;28:121-2.

Amitabh Jena,
R. Patnayak,
A.K. Chowhan.
${ }^{2}$
Departments of ${ }^{1}$ Surgical Oncology,
${ }^{2}$ Pathology,
Sri Venkateswara Institute of Medical Sciences,
Tirupati

Received: 23 September, 2012.

Jena A, Patnayak R, Chowhan AK. Doctor as a healer. J Clin Sci Res 2013;2:119. 